\title{
A Case of Rumination Documented by Using High-resolution Impedance Manometry
}

\author{
Tae Hee Lee
}

Institute for Digestive Research, Soonchunhyang College of Medicine, Seoul, Korea

A 40-year-old male with normal intelligence was referred for oral malodor. He first noticed his oral malodor because his wife had pointed out his bad breath about 7 years ago. He undertook some periodontal treatment such as scaling. His medical history was unremarkable. Esophagogastroduodenoscopy was performed and then revealed reflux esophagitis of minimal changes. His primary care physician started treatment with pantoprazole and mosapride. However, his oral malodor did not decrease. The patient reported frequent postprandial regurgitation and reswallowing of the regurgitated material. Under the clinical impression of rumination syndrome, high-resolution impedance manometry (HRIM) was performed after the patient was provided with some meal. HRIM revealed reflux event that was associated with an increase in intragastric pressure (gastric strain), which was compatible with rumination (Figure). The patient was instructed to take inspiratory and expiratory breaths with the abdominal muscles, keeping the chest motionless. He was encouraged to practice the diaphragmatic breathing during and after eating. He also was given baclofen of $10 \mathrm{mg}$ preprandially for 4 weeks. He eventually reported decreased frequency of regurgitation and heard improved oral malodor from his wife 8 weeks later.

HRIM is useful to diagnose rumination especially in case of diagnostic uncertainty or poor patient's acceptance on a possible diagnosis. ${ }^{1}$ Diaphragmatic breathing is known as the mainstay of

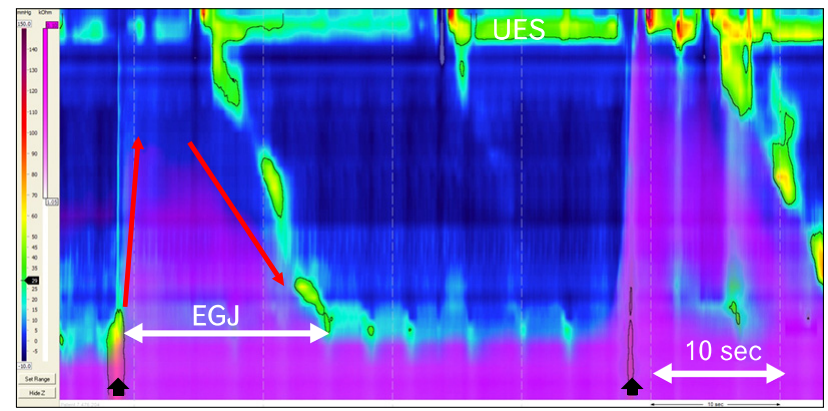

Figure. High-resolution impedance manometry of a patient with rumination syndrome. Two rumination episodes (black arrows) are observed as a rise in the intragastric pressure on the high-resolution manometry color plot associated with retrograde intra-esophageal flow on impedance color plot.

treatment. Baclofen is reported to increase postprandial pressure of lower esophageal sphincter and to inhibit transient lower esophageal sphincter relaxations. ${ }^{2}$ Therefore baclofen is considered to be potentially beneficial in the treatment of rumination. ${ }^{3}$

\section{References}

1. Tack J, Blondeau K, Boecxstaens V, Rommel N. Review article: the pathophysiology, differential diagnosis and management of rumination

Received: January 18, 2013 Revised: February 3, 2013 Accepted: February 5, 2013

(c) This is an Open Access article distributed under the terms of the Creative Commons Attribution Non-Commercial License (http://creativecommons. org/licenses/by-nc/3.0) which permits unrestricted non-commercial use, distribution, and reproduction in any medium, provided the original work is properly cited.

*Correspondence: Tae Hee Lee, MD

Institute for Digestive Research, Soonchunhyang College of Medicine, 59, Daesagwan-ro, Yongsan-gu, Seoul 140-743, Korea

Tel: +82-2-709-9691, Fax: +82-2-709-9696, E-mail: iman0825@schmc.ac.kr

Financial support: None.

Conflicts of interest: None. 
syndrome. Aliment Pharmacol Ther 2011;33:782-788

2. Zhang Q, Lehmann A, Rigda R, Dent J, Holloway RH. Control of transient lower oesophageal sphincter relaxations and reflux by the $\mathrm{GABA}(\mathrm{B})$ agonist baclofen in patients with gastro-oesophageal reflux disease. Gut 2002;50:19-24.
3. Blondeau K, Boecxstaens V, Rommel N, et al. Baclofen improves symptoms and reduces postprandial flow events in patients with rumination and supragastric belching. Clin Gastroenterol Hepatol 2012;10: 379-384. 